\title{
Effect of $\mathrm{Lu}_{3} \mathrm{Al}_{5} \mathrm{O}_{12}: \mathrm{Ce}^{3+}$ and $(\mathrm{Sr}, \mathrm{Ca}) \mathrm{AlSiN}_{3}: \mathrm{Eu}^{2+}$ Phosphor Content on Glass Conversion Lens for High-Power White LED
}

\author{
Hyo-Sung Lee****, Jong Hee Hwang*, Tae-Young Lim*, Jin-Ho Kim*, Dae-Woo Jeon*, \\ Hyun-Suk Jung**; and Mi Jai Lee ${ }^{*, \dagger}$ \\ *Optic \& Display Material Team, Korea Institute of Ceramic Engineering and Technology, Jinju 660-031, Korea \\ **Department of Materials science and Engineering, Sungkyunkwan University, Suwon 440-760, Korea
}

(Received January 20, 2015; Revised March 18, 2015; Accepted March 24, 2015)

\begin{abstract}
Currently, the majority of commercial white LEDs are phosphor converted LEDs made of a blue-emitting chip and YAG yellow phosphor dispersed in organic silicone. However, silicone in high-power devices results in long-term performance problems such as reacting with water, color transition, and shrinkage by heat. Additionally, yellow phosphor is not applicable to warm white LEDs that require a low CCT and high CRI. To solve these problems, mixing of green phosphor, red phosphor and glass, which are stable in high temperatures, is common a production method for high-power warm white LEDs. In this study, we fabricated conversion lenses with LUAG green phosphor, SCASN red phosphor and low-softening point glass for high-power warm white LEDs. Conversion lenses can be well controlled through the phosphor content and heat treatment temperature. Therefore, when the green phosphor content was increased, the CRI and luminance efficiency gradually intensified. Moreover, using high heat treatment temperatures, the fabricated conversion lenses had a high CRI and low luminance efficiency. Thus, the fabricated conversion lenses with green and red phosphor below $90 \mathrm{wt} \%$ and $10 \mathrm{wt} \%$ with a sintering temperature of $500^{\circ} \mathrm{C}$ had the best optical properties. The measured values for the CCT, CRI and luminance efficiency were $3200 \mathrm{~K}, 80$, and $85 \mathrm{~lm} / \mathrm{w}$.
\end{abstract}

Key words : Remote phosphor, White LED package, Color glass, Conversion Lens, Phosphor

\section{Introduction}

$\mathrm{L}$ ighting has been consistently developed from the past and disseminated throughput the world, while being considered as essential equipment for our daily life. In comparison with incandescent lamp and fluorescent lamp as the forerunners of lighting, white LED based on InGaN is being widely used for such areas as indoor lamps, outdoor lamps, urban lighting, automotive and train lights, LCD backlights, etc., since it has many advantages such as high energy efficiency, long life, freedom from pollution, small size, etc. ${ }^{1-4)}$ The most general fabrication method for the white LED involves packaging together of blue LED chip and yellow phosphor for white light emission. ${ }^{5,6}$ Since such method exhibits a high Correlated Color Temperature (CCT) and a low Color Rendering Index(CRI), however, it is difficult to produce warm white light which is applied primarily in household lighting. Hence, warm white LED's are being fabricated by using green phosphor and red phosphor capable of producing a low CCT and a low CRI. ${ }^{7,8)}$ Here, when green phosphor and red phosphor are mixed for use, optical characteristics can be degraded due to interference between two phosphors, etc. Thus, evaluation of character-

\footnotetext{
${ }^{\dagger}$ Corresponding author : Mi Jai Lee

E-mail : im1004@kicet.re.kr

Tel : +82-55-792-2482 Fax : +82-55-792-2492
}

istics was made by varying content of green phosphor and red phosphor to check for such problem. Also, as silicone is employed in the existing fabrication method for conversion lenses, methyl group is separated from silicone with a low glass transition temperature $\left(\mathrm{T}_{\mathrm{g}}\right)$ by the heat of $150^{\circ} \mathrm{C}$ generated in the LED chip at this time, causing defects such as transmittance reduction and color conversion phenomenon. ${ }^{9)}$ Such defects result in reduction of luminance efficiency and shifting phenomenon of color coordinates to degrade performance of optical functions for white LED's. ${ }^{10,11)}$ To provide a solution for such problems, transparent glass ceramics stable at high temperatures are being developed as a substitute material for silicone to fabricate high-power white LED's. ${ }^{12)}$ Also, glass retains inherent properties in white LED without causing defects for crystal structures and optical characteristics of the phosphor. Because of this, white LED based on glass ceramics has not only reduced optical loss, transmittance loss, and color coordinate shift, but also excellent resistance to thermal shocks and humidity. ${ }^{11)}$ Therefore, in the present study, glass with a low softening point based on $\mathrm{SiO}_{2}-\mathrm{B}_{2} \mathrm{O}_{3}-\mathrm{ZnO}-\mathrm{Al}_{2} \mathrm{O}_{3}$, green phosphor and red phosphor were used, while conversion lenses for remote phosphor type LED's were fabricated by using screen printing method as a simple fabrication process where coating areas and thicknesses can be controlled. ${ }^{13)}$ Conversion lenses according to the screen printing method were fabricated with variations in content and heat 
treatment temperature of the phosphor, followed by evaluation of optical characteristics and optical spectra.

\section{Experimental Procedure}

In the present study, low-melting glass frits as a glass based on $\mathrm{SiO}_{2}-\mathrm{B}_{2} \mathrm{O}_{3}-\mathrm{ZnO}-\mathrm{Al}_{2} \mathrm{O}_{3}$ which has the transition point and the softening point of $450^{\circ} \mathrm{C}$ and $485^{\circ} \mathrm{C}$, respectively, and the thermal expansion coefficient of $8.5 \times 10^{-6} /{ }^{\circ} \mathrm{C}$ were used, while $\mathrm{Lu}_{3} \mathrm{Al}_{5} \mathrm{O}_{12}: \mathrm{Ce}^{3+}$ (LuAG, Daejoo Electronic Materials Co., Ltd., L30) green phosphor and (Sr,Ca)AlSiN ${ }_{3}$ : $\mathrm{Eu}^{2+}$ (SCASN, Daejoo Electronic Materials Co., Ltd., C30A) red phosphor were used as the phosphor, and a solution with mixture of a-terpineol, n-butyl acetate and ethyl cellulose having a low decomposition temperature was selected for the organic binder solution. As a substrate for screen printing, rectangular borosilicate-based glass $\left(\right.$ Eagle $2000^{\mathrm{TM}}$, Corning) substrates of $15 \mathrm{~mm}, 60 \mathrm{~mm}, 0.6 \mathrm{~mm}$ in width, length and thickness, respectively, having a high visible light transmittance of 91.6\% (Eagle2000 ${ }^{\mathrm{TM}}$, Corning) were selected. Paste for coating was prepared by adding $30 \mathrm{wt} \%$ of organic binder with respect to the total weight for the organic binder after uniform mixing of $10 \mathrm{wt} \%$ of glass frits with $90 \mathrm{wt} \%$ of phosphor. Here, green phosphor was changed to $70 \sim 90 \mathrm{wt} \%$, and red phosphor to $30 \sim 10 \mathrm{wt} \%$ with respect to the total phosphor weight, with the changed contents shown in Table 1. Prepared paste was screenprinted twice on the glass substrate by using a screen frame having a $30 \mu \mathrm{m}$-thick emulsion film, followed by drying at $100^{\circ} \mathrm{C}$ for 30 minutes. Dried lenses were then heat treated at $500^{\circ} \mathrm{C}, 550^{\circ} \mathrm{C}, 600^{\circ} \mathrm{C}$ for $2 \mathrm{~h}$ to fabricate conversion lenses. Microstructures of surfaces and cross sections of conversion lenses were observed by using a scanning electron microscope (SEM, JSM-6380, JEOL), while reactions between glass and phosphor along with changes in crystalline phases were analyzed by using an X-ray diffraction analyzer (XRD, D/ max-2500/PC, Rigaku corporation) under the condition of $40 \mathrm{kV}, 200 \mathrm{~mA}$. transmittance of visible light domain was measured with uv-vis spectrophotometer (V-570, JASCO), while optical characteristics of light spectrum and correlated color temperature (CCT), color rendering index (CRI), luminance efficiency were measured by using an integrating sphere 1M (LMS-400IPT, J\&C Technology), a spectrograph (JCS-400, J\&C Technology), and power supply.

\section{Results and Discussion}

Microstructure of a fabricated conversion lens is shown in

Table 1. Content of Green Phosphor and Red Phosphor in Phosphor

\begin{tabular}{ccc}
\hline Sample ID & Green phosphor (wt\%) & Red phosphor (wt\%) \\
\hline G7R3 & 70 & 30 \\
G8R2 & 80 & 20 \\
G9R1 & 90 & 10 \\
\hline
\end{tabular}

Fig. 1. The fabricated conversion lens had phosphor to be uniformly laminated, forming a coating film with the thickness shown to be $30 \sim 35 \mu \mathrm{m}$. When surfaces of the fabricated lens are examined, observation could be made that round-shaped green phosphor and square-shaped green phosphor were distributed in a uniformly mixed condition irrespective of content and heat treatment temperature of phosphors and that glass was melted to permeate between the phosphors. With an increase in heat treatment temperature, melting of the glass progressed further and roundshaped green phosphor particles could be affirmed to multiply, the greater the content of green phosphor.

Shown in Fig. 2 is the measurement result of X-ray diffraction (XRD) as a function of phosphor content and heat treatment temperature. For all compositions of the fabricated conversion lens, crystalline phase peaks for $\mathrm{Lu}_{3} \mathrm{Al}_{5}$ $\mathrm{O}_{12}: \mathrm{Ce}^{3+}$ of green phosphor and $(\mathrm{Sr}, \mathrm{Ca}) \mathrm{AlSiN}_{3}: \mathrm{Eu}^{2+}$ of red phosphor were observed, while no second phases were observed as no reaction occurred between glass and phosphor. Since amount of the red phosphor was reduced as content of the green phosphor was increased, the intensity of

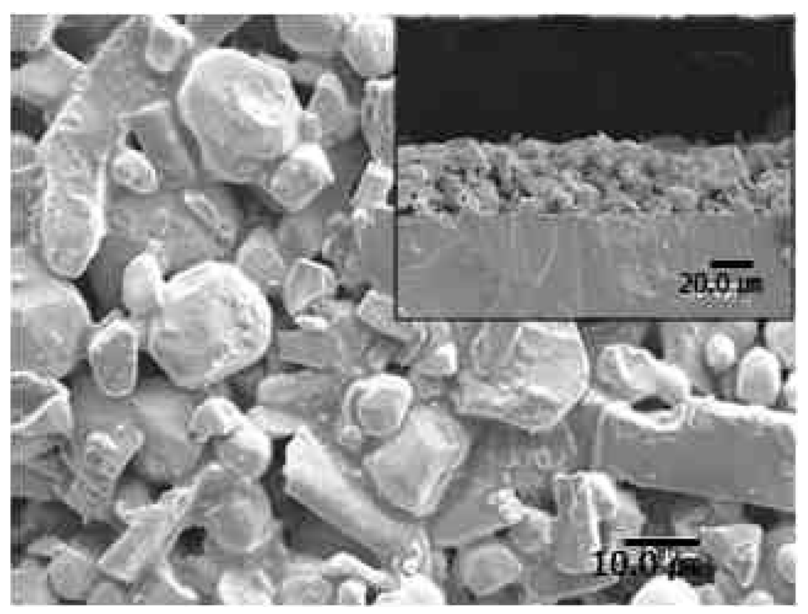

Fig. 1. SEM image of the fabricated conversion lens.

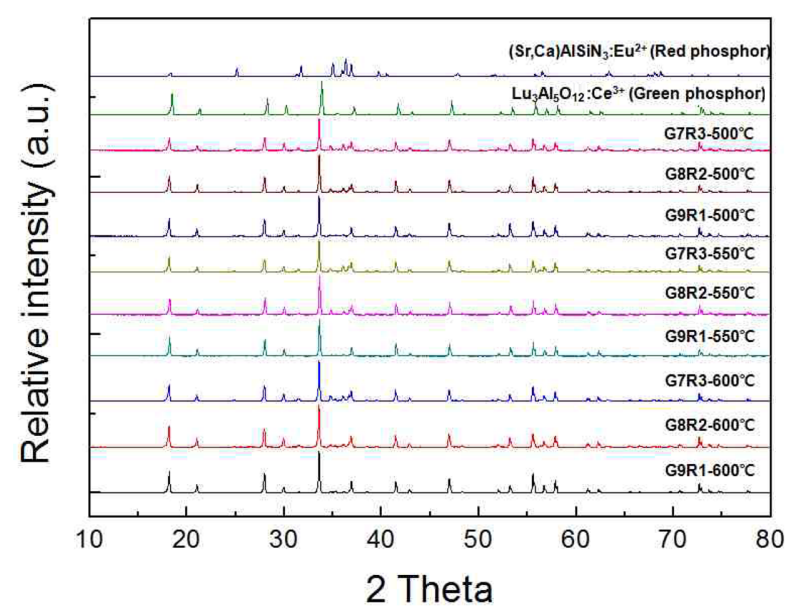

Fig. 2. X-ray patterns of the conversion lens as a function of content of phosphor and heat treatment temperature. 
$(\mathrm{Sr}, \mathrm{Ca}) \mathrm{AlSiN}_{3}: \mathrm{Eu}^{2+}$ crystal peaks could be affirmed to be reduced. Also, as the intensity of $(\mathrm{Sr}, \mathrm{Ca}) \mathrm{AlSiN}_{3}: \mathrm{Eu}^{2+}$ crystal peaks was reduced with an increase in heat treatment temperature so as to exhibit the lowest crystallinity at $600^{\circ} \mathrm{C}$. This is attributed to the fact that inter-diffusion occurs easily between $(\mathrm{Sr}, \mathrm{Ca}) \mathrm{AlSiN}_{3}: \mathrm{Eu}^{2+}$ as the red phosphor and $\mathrm{SiO}_{2}$ as the major glass composition so that $\mathrm{Si}^{4+}$ ions of the amorphous phase infiltrates the crystalline phase of $(\mathrm{Sr}, \mathrm{Ca}) \mathrm{AlSiN}_{3}: \mathrm{Eu}^{2+}$. Also, since occurrence of inter-diffusion in such phosphor causes loss of inherent properties of the phosphor, heat treatment at lower temperatures is reported to be useful for white LED's. ${ }^{14,15)}$

Integrating sphere transmittance in the visible light domain for the conversion lenses fabricated as a function of content and heat treatment temperature of the phosphor is shown in Fig. 3. Because of the use of low-melting glasses at a temperature below $500^{\circ} \mathrm{C}$, there was no change in transmittance dependent on contents, and the transmittance was increased with an increase in content of the green phosphor. While this is due to the fact that refractive indices are high in the order of glass, green phosphor, and red phosphor, much light scattering occurs to cause problems such as reduction of transmittance if a difference in refractive indices is increased. Therefore, when the content of green phosphor with a relatively small difference in refractive index from that of glass is low in conversion lenses, transmittance is considered to increase as an overall difference in refractive indices is reduced so as to reduce light scattering.

Shown in Fig. 4 are photoluminescence spectra as a function of phosphor content and heat treatment temperature. As the content of green phosphor was reduced, a peak shift to red color occurred due to an increase in the intensity of red light, while the intensity of blue light was reduced at
$450 \mathrm{~nm}$. This is considered attributable to the fact that the amounts of blue light absorbed and emitted from each phosphor are varied with a change in the contents of each phosphor. Also, whereas a transition of $4 \mathrm{f}^{7} \rightarrow 4 \mathrm{f}^{6} 5 \mathrm{~d}^{1}$ in $\mathrm{Ce}^{3+}$ occurs at $347 \mathrm{~nm}$ and $450 \mathrm{~nm}$ for the green phosphor $\mathrm{Lu}_{3} \mathrm{Al}_{5} \mathrm{O}_{12}: \mathrm{Ce}^{3+}$, and green light is emitted in a wide range of $450 \sim 650 \mathrm{~nm}$, a transition of $4 \mathrm{f}^{7} \rightarrow 4 \mathrm{f}^{6} 5 \mathrm{~d}^{1}$ in $\mathrm{Eu}^{2+}$ occurs in the section of $300 \sim 550 \mathrm{~nm}$ for the red phosphor $(\mathrm{Sr}, \mathrm{Ca})$ $\mathrm{AlSiN}_{3}: \mathrm{Eu}^{2+}$ to emit red light at $620 \sim 650 \mathrm{~nm} .^{16-17)}$ Eventually, two colors of light are overlapped at $450 \sim 550 \mathrm{~nm}$, and the red phosphor is known to re-absorb light emitted by the green phosphor. Therefore, in the case of G7R3, the green light could be affirmed to have a remarkably low intensity despite of having a not so small amount of green phosphor.

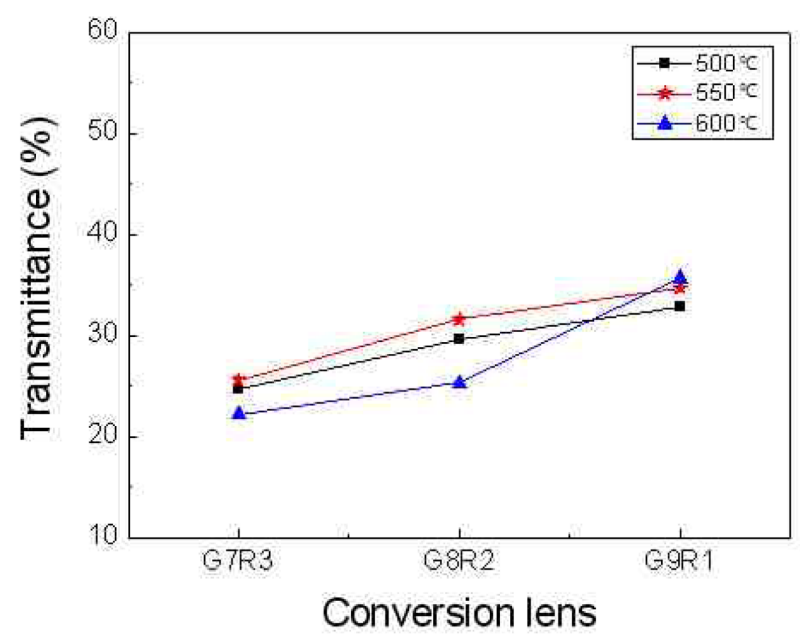

Fig. 3. Transmittance of the conversion lens as a function of content of phosphor and heat treatment temperature.
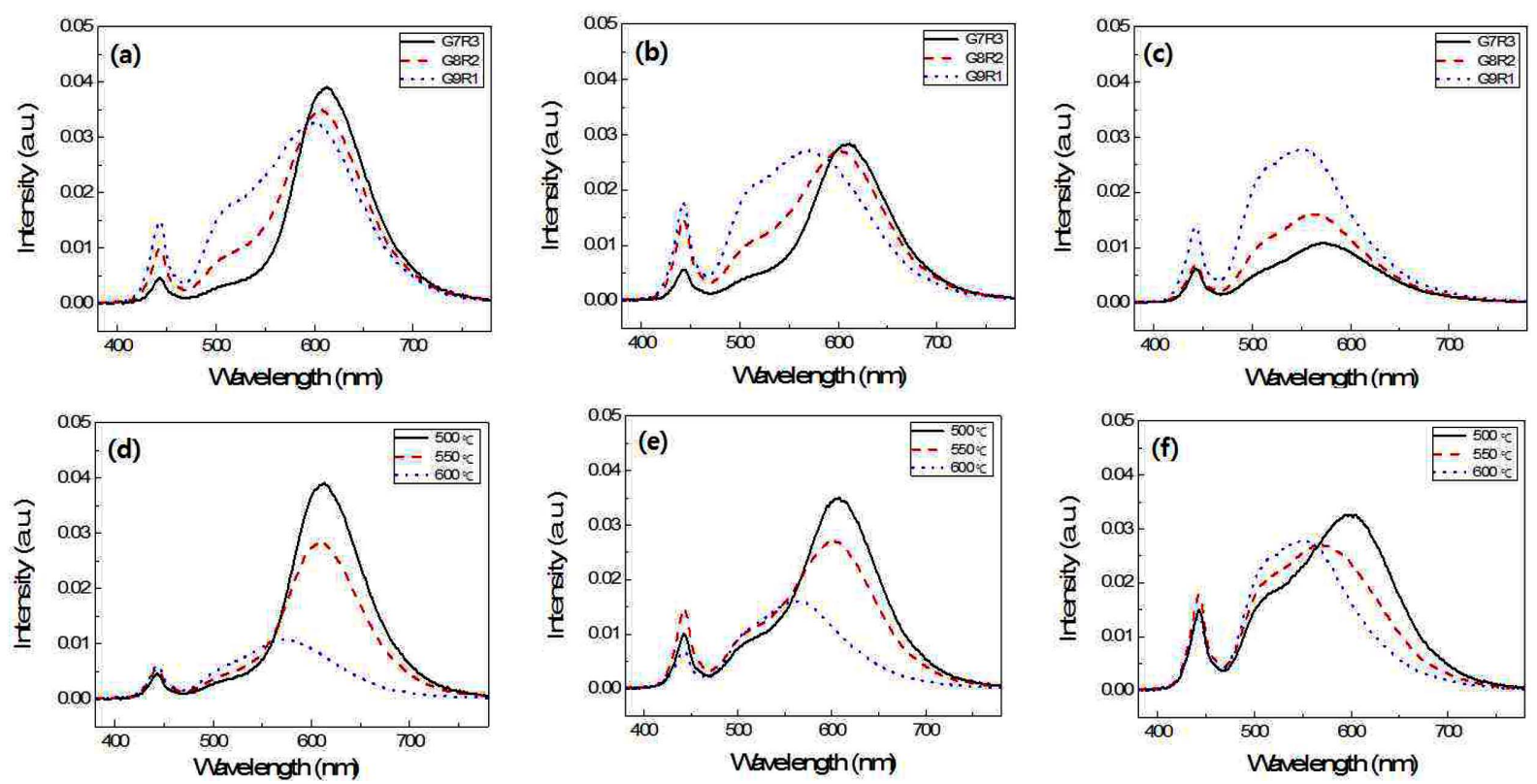

Fig. 4. The photoluminescence (PL) spectra of the conversion lens as a function of content of phosphor and heat treatment temperature: (a) $500^{\circ} \mathrm{C}$, (b) $550^{\circ} \mathrm{C}$, (c) $600^{\circ} \mathrm{C}$, (d) $\mathrm{G} 7 \mathrm{R} 3$, (e) G8R2, and (f) G9R1. 
However, the intensity was reduced in all sections at $600^{\circ} \mathrm{C}$ although the content of red phosphor was increased, which is due to occurrence of thermal quenching phenomenon where light emission efficiencies of the phosphor were reduced with a temperature rise caused by thermal energy. Particularly, in the case of red phosphor, the phenomenon of thermal quenching is more severe than that for green phosphor so that internal quantum efficiencies are known to be further reduced. ${ }^{14)}$ As the result, the photoluminescence spectra as a function of heat treatment temperature given in Fig. 4 (d), (e) and (f) show that the intensity of green light was increased, the higher the heat treatment temperature, while the intensity of red light was remarkably reduced causing a peak shift to green color. Also, re-absorption from green light due to reduction in internal quantum efficiency of red phosphor was markedly reduced as well to exhibit such photoluminescence spectra as shown above.

Shown in Fig. 5 is a shift of CIE color coordinates as a function of phosphor content and heat treatment temperature. While the color coordinate of green phosphor $\mathrm{Lu}_{3} \mathrm{Al}_{5} \mathrm{O}_{12}: \mathrm{Ce}^{3+}$ originally shows $(0.361,0.573)$ and that of red phosphor ( $\mathrm{Sr}, \mathrm{Ca}) \mathrm{AlSiN}_{3}: \mathrm{Eu}^{2+}$ shows $(0.5254,0.2958)$, the color coordinates were shifted toward green color as green phosphor content were increased and heat treatment temperature raised, with G9R1-500 and G8R2-550 showing warm white, G9R1-550 cool white, and G9R1-600 neutral white.

Figure 6 shows optical characteristics of a conversion lens as a function of changes in phosphor content and heat treat- ment temperature, where (a) shows correlated color temperature (CCT), (b) average color rendering index (CRI), (c)luminance efficiency. Color rendering indices were reduced at $600^{\circ} \mathrm{C}$ due to thermal quenching phenomenon as green phosphor was increased. Excluding this case, all of correlated color temperature, color rendering index, luminance efficiency were increased as the content of green phosphor was increased. Such results are caused by the fact that the green phosphor shows higher values of correlated color temperature, color rendering index, and luminance efficiency than the red phosphor. Also, when various phosphors are mixed, it is known that a phosphor re-absorbs the light emitted by another phosphor, causing overlapping of the light emission spectra, resulting in degraded quality of color sense and lowered luminance efficiency. In the present study, the results as presented in Fig. 6 have been observed since the amounts of green light re-absorbed upon reduction of red phosphor are decreased as the red phosphor reabsorbs light emitted by the green phosphor. ${ }^{18)}$ Depending on heat treatment temperature, light emission from the green color is the higher whereas that from the red color is the lower, the higher the heat treatment temperature, while correlated color temperature as well as luminance efficiency were reduced due to the lowering of internal quantum efficiency in red phosphor.

\section{Conclusions}

In the present study, conversion lenses have been fabri-
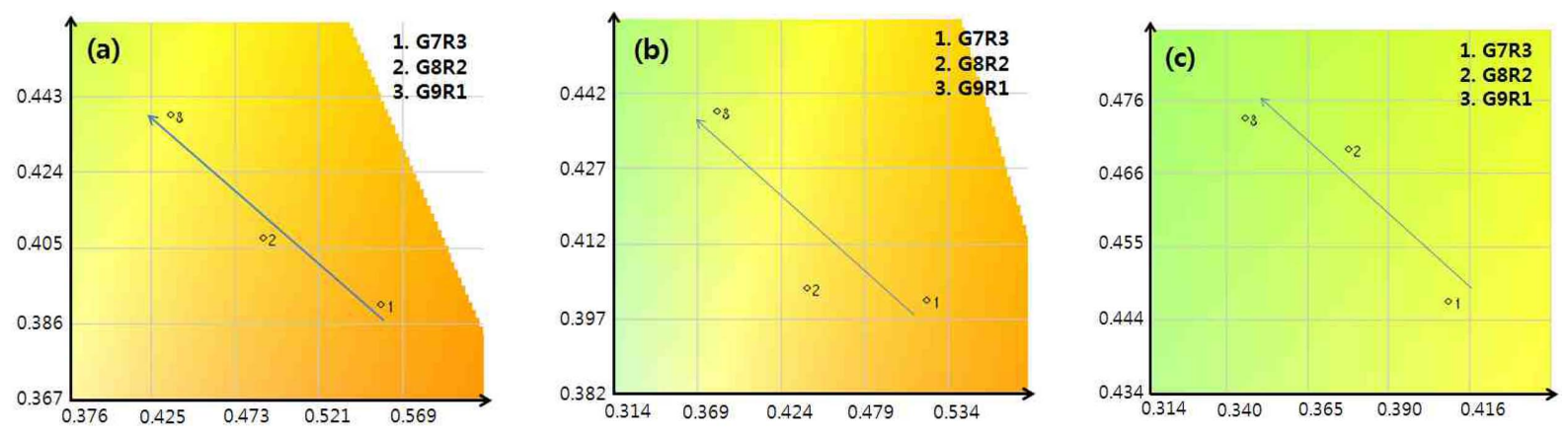

Fig. 5. CIE color coordinate of conversion lens as a function of content of phosphor and heat treatment temperature: (a) $500^{\circ} \mathrm{C}$, (b) $550^{\circ} \mathrm{C}$ and (c) $600^{\circ} \mathrm{C}$.
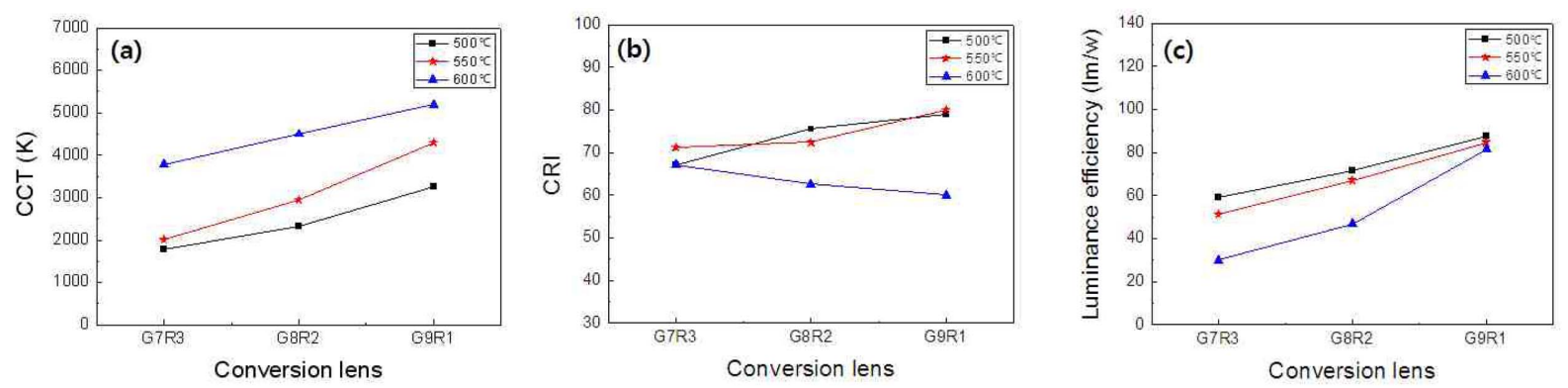

Fig. 6. Optical properties of the conversion lens as a function of content of phosphor and heat treatment temperature: (a) CCT (K), (b) CRI and (c) Luminance efficiency $(\mathrm{lm} / \mathrm{w})$. 
cated with variations in the contents of green phosphor and of red phosphor by using a screen printing method. For the fabricated lenses, amounts of absorbed and emitted light were varied accompanied by an increase in transmittance as the content of green phosphor was increased, while correlated color temperature (CCT), color rendering index (CRI), luminance efficiency were increased along with a change in photoluminescence spectrum due to re-absorption from red phosphor. In addition, color coordinates could be controlled by a change in phosphor contents, allowing production of warm white of $3000 \mathrm{~K}$, cool white of $4100 \mathrm{~K}$, and neutral white of $5000 \mathrm{~K}$. While inherent properties are lost due to thermal quenching phenomenon of the phosphor when heat treatment temperature is raised, reduction in XRD intensity and intensity of light emission spectrum could be affirmed particularly when the content of $(\mathrm{Sr}, \mathrm{Ca}) \mathrm{AlSiN}_{3}: \mathrm{Eu}^{2+}$ is high as a red phosphor sensitive to heat, according to which correlated color temperature was increased and luminance efficiency reduced. Consequently, the conversion lens with heat treatment at $500^{\circ} \mathrm{C}$ at a content ratio of $90 \mathrm{wt} \%$ for green phosphor, and $10 \mathrm{wt} \%$ for red phosphor exhibited warm white light of $3200 \mathrm{~K}$, CRI of 80 , luminance efficiency of $85 \mathrm{~lm} / \mathrm{w}$, showing the best optical characteristics. Based on the results of the present study, production of desired white color as a function of content of green phosphor and red phosphor and of heat treatment temperature has been shown to be possible, while change phenomenon and optical characteristics could be affirmed according to each condition.

\section{Acknowledgments}

The present study has been performed with support for Highly heat-resistant color conversion composite ceramic materials for high-power LED packages' (Task No.: 10047778) as a 2013 technology development project for strategic core materials.

\section{REFERENCES}

1. S. Nakamura, T. Mukai, and M. Senoh, "Candela-Class High-Brightness InGaN/AlGaN Double-Heterostructure Blue-Light-Emitting Diodes," Appl. Phys. Lett., 64 1687-89 (1994).

2. S. Aanegola, J. Petroski, and E. Radkov, "Let There Be Light," SPIE, 10 16-18 (2003).

3. Y. Narukawa, "White-Light LEDs," Opt. Photonics News., 15 24-29 (2004).

4. C.-Y Shen, K. Li, Q.-L Hou, H.-J. Feng, and X.-Y. Dong, "White LED Based on YAG:Ce,Gd Phosphor and CdSe-ZnS Core/Shell Quantum Dots," IEEE Photon Technol. Lett., 22 [12] 8884-86 (2010).
5. S. Nishiura, S. Tanabe, K. Fujioka, and Y. Fujimoto, "Properties of Transparent Ce:YAG Ceramic Phosphor for White LED,” J. Optic. Mater., 33 688-91 (2011).

6. Y. J. Kim and S. M. Park, " $\mathrm{Eu}^{2+}, \mathrm{Mn}^{2+}$ Co-doped $\mathrm{Ba}_{9} \mathrm{Y}_{2} \mathrm{Si}_{6} \mathrm{O}_{24}$ Phosphors Based on Near-UV-excitable LED Lights," Mater. Res. Bull., 49 469-74 (2014).

7. H. T. Kim, J. H. Kim, J. -K. Lee, Y. C. Kang,C. Sommer, P. Hartmann, P. Pachler, M. Schweighart, S. Tasch, G. Leising, and F. P. Wenzl, "Green Light-Emitting $\mathrm{Lu}_{3} \mathrm{Al}_{5} \mathrm{O}_{12}$ :Ce Phosphor Powders Prepared by Spray Pyrolysis," Mater. Res. Bull., 47 [6] 1428-31 (2012).

8. J. S. Lee, P. Arunkumar, S. Kim, I. J. Lee, H. Lee, and W. B. Im, "Smart Design to Resolve Spectral Overlapping of Phosphor-in-Glass for High-Powered Remote Type White Light-Emitting Devices," Opt. Lett., 39 [4] 762-65 (2014).

9. T. Yanagisawa and T. Kojima, "Long-term Accelerated Current Operation of White Light-Emitting Didoes," $J$. Lumin., 114 39-42 (2005).

10. U. Lafont, H. van Zeijl, and S. van der Zwaag, "Increasing the Reliability of Solid State Lighting Systems Via SelfHealing Approaches: a Review," Microelectron Reliab., 52 71-89 (2012).

11. D. Chen, W. Xiang, X. Liang, J. Zhong, H. Yu, M. Ding, H. $\mathrm{Lu}$, and Z. Ji, "Advances in Transparent Glass-Ceramic Phosphors for White Light-Emitting Diodes-a Review," $J$. Eur. Ceram. Soc., 35 [3] 859-69 (2015).

12. S. Fujita, S. Yoshihara, A. Sakamoto, S. Yamamoto, and S. Tanabe, "YAG Glass-Ceramic Phosphor for White LED (I): Background and Development," Proc. SPIE, 5941 11-17 (2005).

13. T. Nakanishi and S. Tanabe, "Preparation and Luminescence Properties of Glass Ceramics Precipitated with $\mathrm{M}_{2}$ $\mathrm{MgSi}_{2} \mathrm{O}_{7}: \mathrm{Eu}^{2+}(\mathrm{M}=\mathrm{Sr}, \mathrm{Ca})$ Phosphor for White Light Source," IEEE. J. Sel. Top Quantum Electron., 15 1171-80 (2009).

14. L. -Y. Chen, W. -C. Cheng, C. -C. Tsai, J. -K. Chang, Y. -C. Huang, J. -C. Huang, and W. -H. Cheng, "Novel Broadband Glass Phosphors for High CRI WLEDs," Opt. Express, 22 A671-78 (2014).

15. L. -Y. Chen, W. -C. Cheng, C. -C. Huang, Y. -S. Lin, and W. -H. Cheng, "High-Performance Glass Phosphor for WhiteLight-Emitting Diodes Via Reduction of Si-Ce ${ }^{3+}$ :YAG InterDiffusion," Opt. Mater. Express, 4 [1] 121-28 (2014).

16. H. -L. Li, X. -J. Liu, L. -P. Huang, "Luminescent Properties of LuAG:Ce Phosphors with Different Ce Content Prepared by a Sol-gel Combustion Method," Opt. Mater., 29 [9] 113842 (2007).

17. M. R. Krames, "Wavelength Conversion for Producing White Light from High Power Blue LED," U.S. Patent 2010/02890442010.

18. K. Sakuma, K. Omichi, N. Kimura, M. Ohashi, D. Tanaka, and N. Hirosaki, "Warm-White Light-Emitting Diode with Yellowish Orange SiAlON Ceramic Phosphor," Opt. Lett., 29 [9] 2001-03 (2004). 